\title{
Improving Problem Solving and Programming Skills through Learning Games of an Inter-Competition Type
}

\author{
Y.C. Lee, J.Y. Ko, S.B. Kim \\ Department of Computer Education \\ Jeju National University \\ Korea
}

\begin{abstract}
This studyproposes a new learning model for improving problem solving and programming skills. To solve a real world problemusing IT, the problem solving and programming skills are important. In this study, we propose and develop a learning model that can help to improve problem solvingand programming skills, based on computational thinking. The feature of the learning model proposed is to offer learners challenge and interestby presenting the questions into learning games of an inter-competition type after developing the questions that improve the problem solving and programming skills. Also, another feature is to present the questions about algorithm and programming in the various forms and generate the questions dynamically. Especially, by providing an inter-competition game type, due to increase of competitive sense between learners, learners feel relatively less difficulty of problem solving and programming and enable to naturally improve the problem solving and programming skills through competition.
\end{abstract}

Keywords-learning model; competition; problem solving and programming skill; learning game; learner

\section{INTRODUCTION}

As information era in the 21st is becoming, the computer is being closely related more and more with our lives. Recently, in handling most of things, we use the computer. Due to such reason, it is becoming more important to know how to solve a problem given using the computer. However, after the problem is given, it is difficult to learn how to resolve this on the computer. It's because the solution to solve using the computer is not standardized, depending on the problem. Students lack of problem solving capability or programming skills are unable to solve the given questions due to the non-standardized problem solving method. Therefore, It is necessary to develop the variety of questions reflecting the real-world problems and the way to train the problem solving capability and programming skills. However, most of us have a vague sense of fear about programming and think of programming as difficult or hard thing to work on. First of all, it is hard to understand the programming language when we first encounter it because the programming language is another language. When we first learn a new foreign language, the words are unfamiliar and hard to understand, and give us a headache. It applies to learning programming language as well. Motivation is necessary to overcome the difficulties when we learn new things. This study aims to improve problem solving capability and programming skills to solve problems using computer by giving a weight on the game specific elements through a competitive game to stimulate interest.

\section{RELATED RESEARCH}

There have been many studies on the programming capability. For example, there has been a study indicates that it is possible to enhance programming skills by using a program called SCRATCH [1]. Also, one study examined how to develop a program to enhance program skills [2]. Besides those studies mentioned, there has been a study on developing and applying IDEAL-TRIZ learning program as a way to strengthen technical problem solving capability. According to the study, it should be able to draw the learners' interests to increase the learning effect [3]. Another research examined how to make an information education program to improve creative problem solving skills [4]. A theoretical review on the activity model to improve problem solving capability of students in rural areas and developing a program that fits the purpose has been conducted [5].However, this study, unlike those studies introduced above, adds the game elements in the inter-competitive form and aims to draw the learning effect by stimulating competitive spirit among learners, and make them feel a sense of challenge.

\section{ANALYSIS}

To provide a method to enhance problem solving capability and programming skills through learning game in an intercompetitive form, this study was conducted following the four phases listed below [Table 1].

TABLE I. FOUR PHASES FOR STUDY

\begin{tabular}{|c|c|c|c|}
\hline $\begin{array}{l}\text { Phase 1: } \\
\text { Analysis }\end{array}$ & $\begin{array}{c}\text { Phase 2: } \\
\text { Design }\end{array}$ & $\begin{array}{c}\text { Phase } 3: \\
\text { Implementation }\end{array}$ & Phase 4: Test \\
\hline $\begin{array}{l}\text { - Analysis of } \\
\text { technology } \\
\text { and } \\
\text { environment. } \\
\text { - Analysis of } \\
\text { related } \\
\text { literatures. } \\
\text { - Analysis of } \\
\text { existing } \\
\text { learning } \\
\text { games. }\end{array}$ & $\begin{array}{l}\text { - Design a } \\
\text { learning } \\
\text { game flow } \\
\text { diagram. } \\
\text { - Design a } \\
\text { game } \\
\text { learners' } \\
\text { interface. } \\
\text { - Design a } \\
\text { database. }\end{array}$ & $\begin{array}{l}\text { - Database } \\
\text { realization. } \\
\text { - Developing } \\
\text { question types. } \\
\text { - Developing } \\
\text { questions. }\end{array}$ & $\begin{array}{l}\text { - Evaluate and } \\
\text { revise the } \\
\text { simulation } \\
\text { repeatedly. } \\
\text { - Continuously } \\
\text { adds questions } \\
\text { for each type. }\end{array}$ \\
\hline
\end{tabular}




\section{A. Learning Game Flow Chart}

Figure $\mathrm{I}$ is an overall learning flow diagram of a program designed in this study. You will be entering the waiting room when you first enter the user name and password to login. Then, participate in the game room already made if there is the opponent you want to play with, or make a game room and start the game when an opponent comes into the game room. If you are unable to find an opponent you want to play with, find an opponent has a similar rank using the partner search button and start the game. As you start the game, five questions that are dynamically generated in different question types will be set. After solving the problems, the score of your and your opponent will be compared and the one earned a higher score will win. Rank will rise when you win, and rank will drop when you lose. You can have a rematch or go back to the waiting room if you don't want a rematch. If you want to quit the game, click the out button in the waiting room to finish the game.

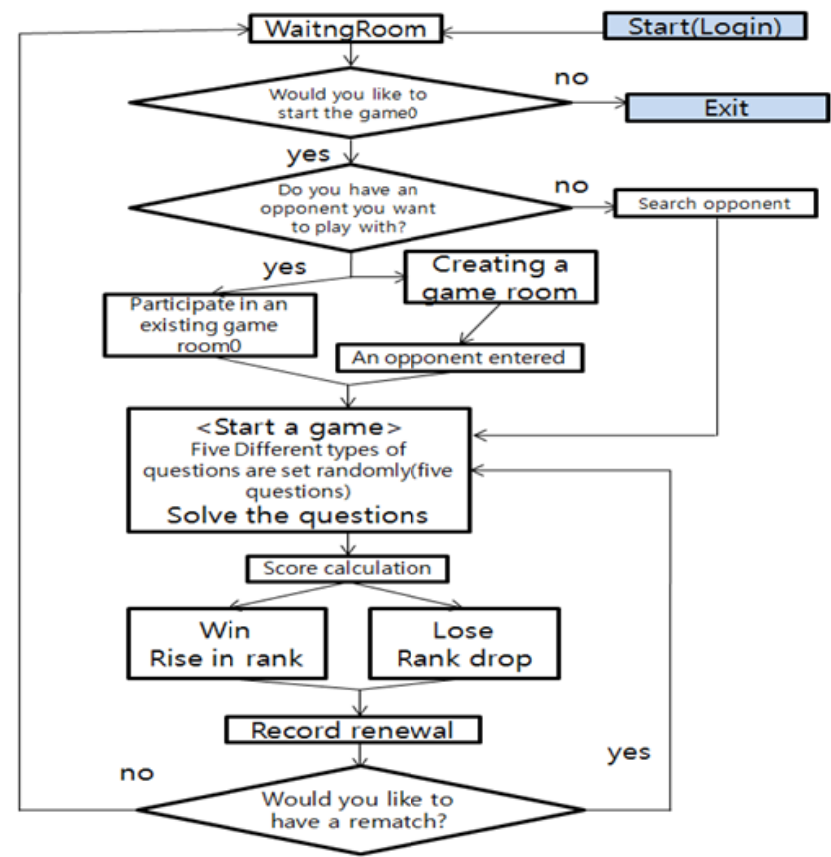

FIGURE I. LEARNING GAME FLOW DIAGRAM

\section{DESIGN}

\section{A. Learning Game Content}

This educational game has its basis on the contents included in major subjects, such as, algorithm, Java, C-language, PHP, and data structure, associated college level problem solving and programming language. The purpose of this educational game is to ensure to master the basics of programming using Java, Clanguage, and PHP and effectively learn data structure and algorithm to enhance problem solving capability.

\section{B. Competition Form}

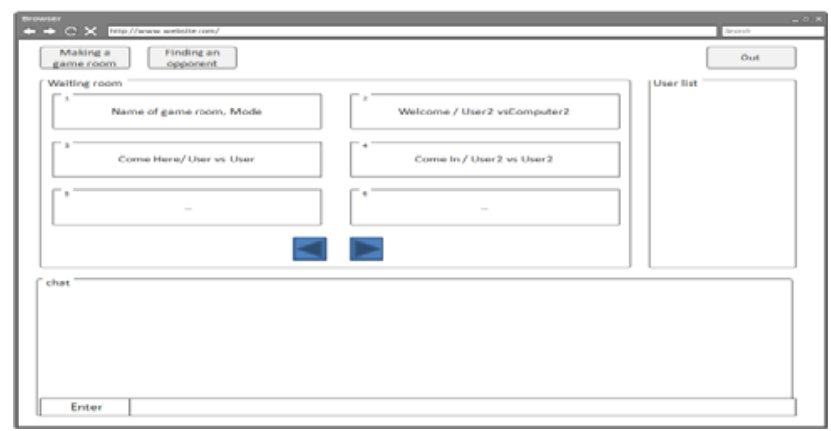

FIGURE II. WAITING ROOM

As you login, you will see the screen as described above. This is a state to wait before you start the game. You can chat with other opponents, make a game room, or participate in a game room created by others. If you click the search button, you will be paired with an opponent has a similar rank and entered into a game room.

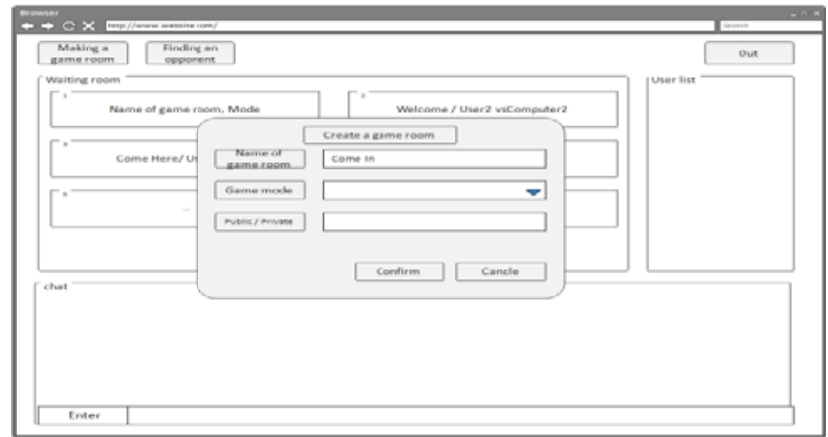

FIGUREIII. MAKING A ROOM

Figure 3 describes the process to make a game room. You can set the room name, game mode, and whether to make the room public or private when you create a game room.

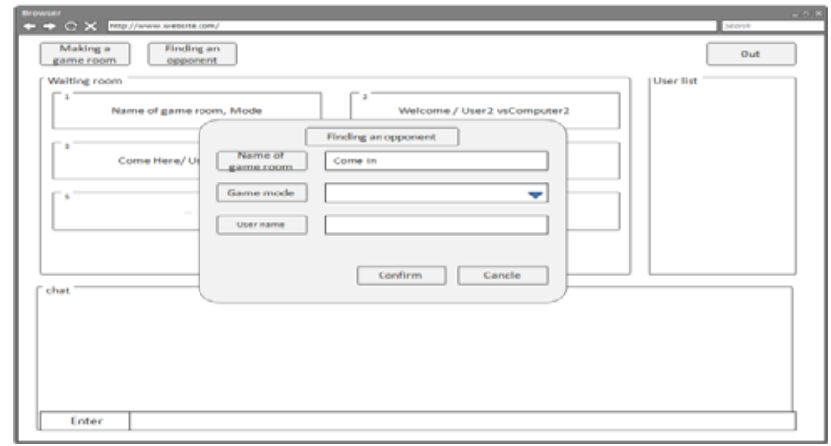

FIGUREIV. FINDING OPPONENT

Figure 4 describes the process to find an opponent using the finding opponent button. If there is an opponent satisfies one of the conditions, name of the game room, game mode, or user name, it will move you to the game room made by the opponent. 


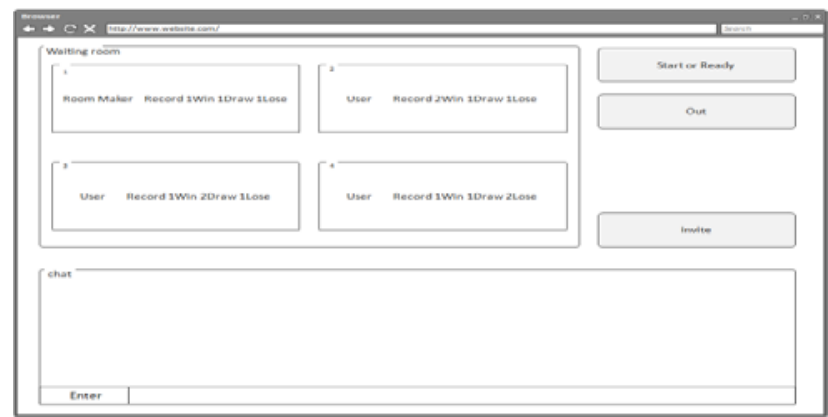

FIGUREV. COMPETING ROOM SCREEN

Figure 5 is a created game room screen. The learner who made the game room can start the game when is ready, or can expel opponents if the learner who made the game room does not want to play the game with the opponents. When the game starts, random types of questions will be selected, and the selected questions that are dynamically deformed will be printed out. From now on, each question type will be described.

\section{Types of Questions}

\section{1) Type (1)}

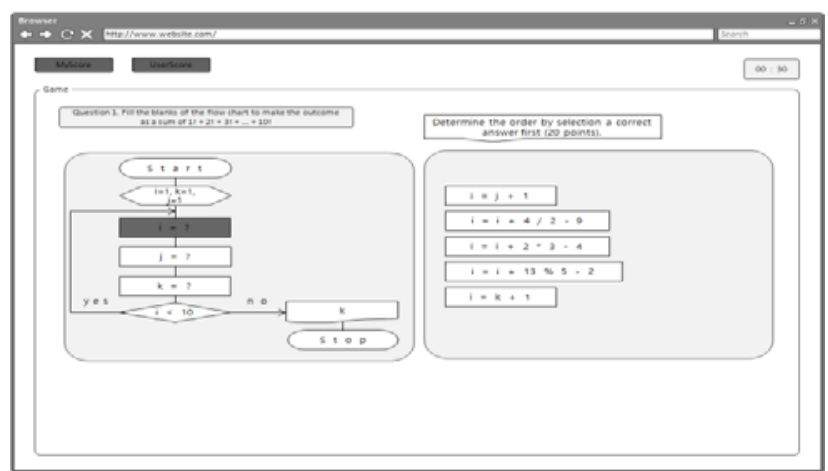

FIGUREVI. FILLING A FLOW CHART TYPE

In this question, the user first fills the blanks gets the next question ahead of the opponent. The user will be able to solve the next question continuously if the user gives the correct answer. If the user gives a wrong answer, the question will be given to the opponent. 20 points will be filled in the first blank, and 10 points in the second blank, and 30 points in the last blank. The way the points are given for each blank adds the element of the game.

\section{2) Type (2)}

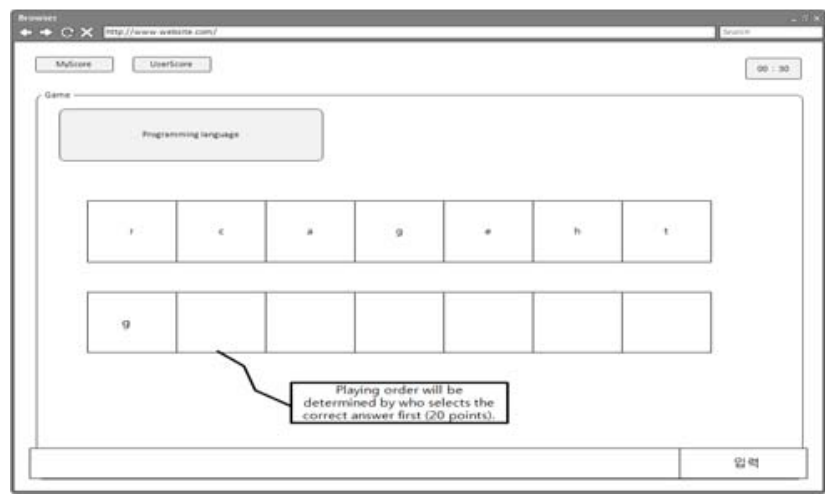

FIGURE VII. PROGRAMMING LANGUAGE TYPE

In this question, the user first fills the first blank will be able to solve the next problem first. The chance to play next question will be given to the opponent if the user gives the correct answer or a wrong answer. 20 points will be filled in the first blank, and 10 points from the second blank. The way the points are given for each blank adds the element of the game.

3) Type (3)

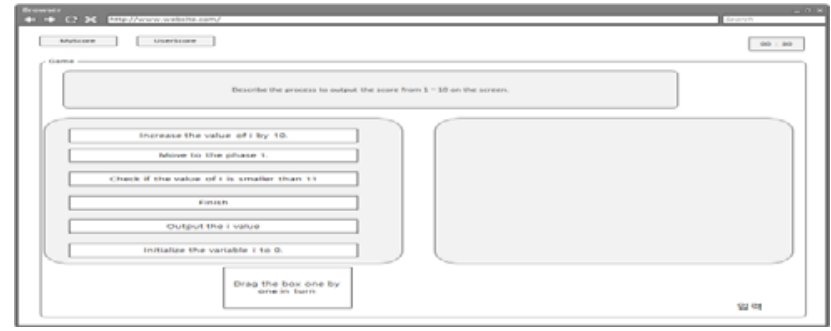

FIGURE VIII. ALGORITHM STEP ARRANGEMENT TYPE

In this question, you have to drag the sentence to be placed in the first place following the order. If you drag the correct sentence first, you can have a chance to place the answer for the next question. If you give the correct answer or a wrong answer, the turn will be given to the opponent. 20 points will be filled in the first blank, and 10 points from the second blank. The way the points are given for each blank adds the element of the game.

4) Type (4)

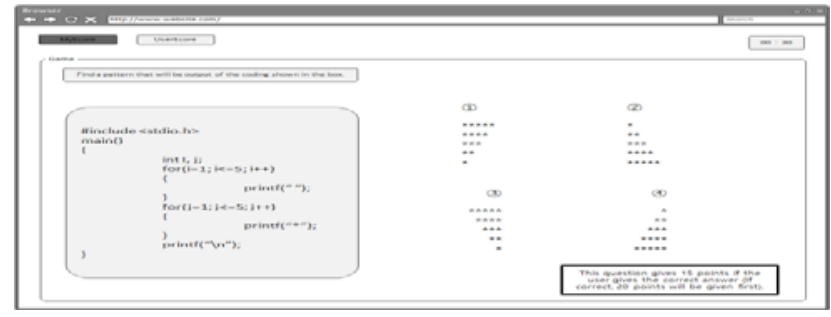

FIGURE IX. OUTPUT RESULT CONFIRMATION TYPE

THIS QUESTION IS A SIMPLE ONE TO REST USER'S MIND. IT'S A MULTIPLE CHOICE QUESTION GIVEN TO EACH USER. IF CORRECT, 10 POINTS WILL BE GIVEN. THERE IS A TIME LIMIT OF 10 20 SECONDS 


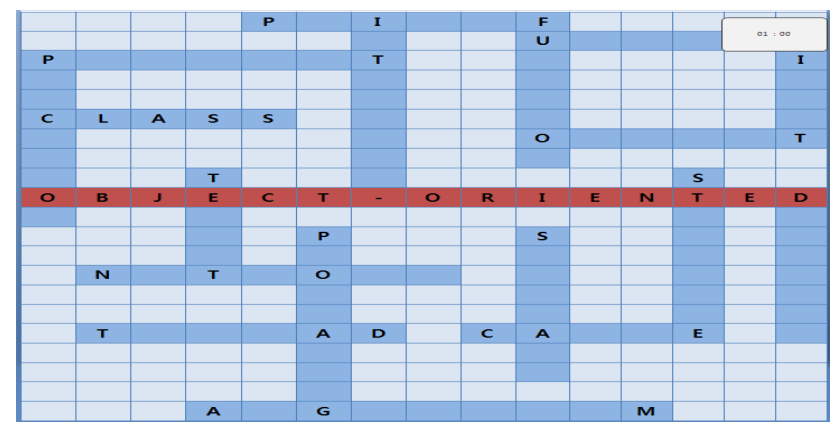

FIGUREX. PUZZLE TYPE

It is a question type that the user solves more questions first earns more points. Each user will have a question on the screen, and the user solves more question in a limited time will earn more points. If the use solves all the questions in one screen, bonus points will be given to the user.

Five kinds of questions of each question type will be selected randomly. All the questions are dynamic, so it can be changed a little by using the problem or answer.

\section{CONCLUSION}

This study provides five kinds of question types as providing the learning model in the form of the competitive game to enhance programming skills. The dynamically changing questions help to draw learners' sense of accomplishment and contribute to stimulating motivation by drawing learners' competitive spirit and sense of challenge through the competitive game. The game design is currently completed, and a prototype is on development. The effect of this learning model will be tested by applying the game after the prototype is completely developed.

\section{REFERENCES}

[1] Ahn, K. M., Sohn, W. -S. \& Choi, Y.-C., The Effect of Scratch Programming Education on Learning-Flow and Programming Ability for Elementary Students.Journal of Korea Association of Information Education, 15(1), 2011.

[2] Choi, J. W \& Lee, Y. J., Development of Education Programs for Improving Programming Learning Skills.Proc. of 2014 Summer Conference of the Korean Association of Computer Education,18(2), 2014.

[3] Lee, J. G \& Choi, Y.-H., The Development and application Effect of IDEAL-TRIZ Learning Program to Improve Technological ProblemSolving Capability for Elementary School Students. Journal of the Korean Association of Practical Arts Education, 23(2),2010.

[4] Lee, Y., Lim, U. \& Lee, E., Development of Information Education Program for Enhancing Creativity. Journal of the Korean Association of Computer Education. 13(1), 2010.

[5] Jeong, E., Moon, C., Hong, S. \& Park, J., A Study on the Development of Activity Model and Program for Enhancing Creative Problem Solving Capability of the Students in Jeju Area. Journal of Korea AcademiaIndustrial Cooperation Society. Fall, 2010. 